\title{
RELATOS DE PESQUISAS
A INFLUÊNCIA DO COMPORTAMENTO IMPULSIVO E
PROCRASTINADOR NA TOMADA DE DECISÃO
FINANCEIRA SOB A ÓTICA DA
DESVALORIZAÇÃO POR ATRASO
}

\author{
André Tonin Ferrari \\ Mestre em Administração pela Universidade Metodista de São Paulo, \\ Brasil. Professor da Universidade Estácio de Sá, Brasil. \\ E-mail: andre.ferrari@estacio.br
}

Alexandre Cappellozza

Doutor em Administração pela Fundação Getúlio Vargas, Brasil. Professor da Universidade Metodista de São Paulo, Brasil.

E-mail: alexandre.cappellozza@metodista.br

\author{
Elmo Tambosi Filho \\ Doutor em Administração pela Universidade Federal de Santa Catarina, \\ Brasil. Professor da Universidade Metodista de São Paulo, Brasil. \\ E-mail: elmotf@hotmail.com \\ Joelson Oliveira Sampaio \\ Doutor em Administração pela Fundação Getúlio Vargas, Brasil. \\ Professor da Fundação Escola de Comércio Álvares e da Fundação \\ Getúlio Vargas, Brasil. \\ E-mail: Joelson.sampaio@fgv.br
}

\begin{abstract}
Resumo
A compreensão dos fatores que influenciam a tomada de decisão individual em diferentes cenários é objeto de diversos estudos científicos. Alguns destes fatores como o comportamento impulsivo e o comportamento procrastinador podem ser fundamentais para que o indivíduo aceite, ou não, desvalorizar determinado valor. Este estudo analisou como estes fatores impactam na tomada de decisão de ofertas promocionais sob diferentes prazos. Por meio de uma abordagem de investigação quantitativa e experimental, os dados foram coletados pela aplicação de um instrumento de pesquisa com obtenção da resposta de 410 respondentes. Os resultados obtidos por esta pesquisa confirmam a influência da procrastinação no processo de tomada da decisão financeira individual em cenários aversivos de oferta. Conclui-se que o comportamento procrastinador afeta a tomada de decisão, conduzindo o indivíduo a não desvalorizar o atraso determinado nos prazos. Além disso, constatou-se que o comportamento impulsivo não ficou evidenciado como componente que possa impactar na decisão financeira do indivíduo nas mesmas ofertas apresentadas aos respondentes.
\end{abstract}

Palavras-chave: Atraso. Decisão. Impulsividade. Procrastinação.

THE INFLUENCE OF IMPULSIVE AND PROCRASTINATING BEHAVIOR ON FINANCIAL DECISION FROM THE PERSPECTIVE OF DELAY DISCOUNTING

\section{Abstract}

The comprehension of individual decision factors in different scenarios has been studied in scientific studies. Some of these factors, such as impulsive and procrastinating behavior may be fundamental for 
the individual to accept, or not, a given offer. This study analyzed how these factors impact the decision process of some offers under different deadlines. Through a quantitative and experimental research approach, data were collected from 410 subjects. Our results confirm the influence of procrastination in individual financial decisions applied to different aversive offerings scenarios. In addition, it was found that the impulsive behavior was not evidenced as a component that could impact financial decisions in those same offers.

Keywords: Delay. Decision. Impulsivity. Procrastination.

\section{INTRODUÇÃO}

Decidir é um processo de escolha de uma opção dentre alternativas que pode ser considerada como recorrente quase todo momento. Tal processo pode envolver situações cotidianas como, por exemplo, decidir qual roupa vestir, ou decisões de outra magnitude como investir ou não em educação, ou realizar investimentos em outras possibilidades. A tomada de decisão é algo frequente no âmbito empresarial. Gestores que não possuem habilidades e conhecimento suficiente podem se comprometer tomando decisões inadequadas em cenários complexos, comprometendo os resultados empresariais (CAPPELLOZZA; SANCHEZ, 2011).

Além disso, sabe-se que há uma tendência nos indivíduos em procurar atalhos mentais durante o processo decisório. Desta forma diferentes aspectos podem influenciar a tomada de decisão individual levando o indivíduo racional a tomar decisões carregadas por um viés cognitivo. Em uma situação racional o processo decisório do indivíduo ocorre de forma diferente de uma situação em que os atalhos mentais são ativados, tendo suas decisões influenciadas por emoções (KAHNEMAN; TVERSKY, 1979).

Por outro lado, a impulsividade também pode afetar a decisão, considerando que a impulsividade se trata de uma tendência à resposta de forma rápida e sem reflexão. A impulsividade tem sido relacionada com consequências negativas como inadimplência, arrependimento pós compra e comprometimento da autoestima. A compra por impulso pode adquirir proporções excessivas e levar o indivíduo a adquirir dívidas financeiras ou a enfrentar distúrbios psicológicos (DITTMAR; BEATTIE; FRIESE, 1996). No entanto, indivíduos tendem a apresentar um comportamento procrastinador, pois acabam prorrogando suas decisões, desta forma perdendo oportunidades que possam ser vantajosas ao indivíduo (HAMASAKI; KERBAUY, 2001).

Os adultos por sua vez procrastinam em tarefas rotineiras como, por exemplo, marcar exames médicos (HAMASAKI; KERBAUY, 2001). Há um aumento desse comportamento na população em geral, indicando que a procrastinação afeta cronicamente $15 \%$ a $20 \%$ da população de indivíduos adultos (HARRIOT; FERRARI, 1996; KACHGAL; HANSEN; NUTTER, 2001).

No contexto empresarial, profissionais que procrastinam tendem a apresentar resultados abaixo do esperado, gerando inclusive desconforto junto aos liderados, pois deixam o cumprimento das atividades para a última hora, correndo o risco de não entregar o trabalho. Apesar de seus impactos negativos na produtividade nas empresas, a procrastinação tem sido pouco explorada pelas pesquisas de comportamento organizacional (WEYMANN, 1988).

A partir desta possibilidade de investigação, apresenta-se a seguinte questão de pesquisa: A impulsividade e a procrastinação, associada ao fenômeno da desvalorização por atraso, podem afetar a tomada de decisões financeiras?

Na próxima seção, apresenta-se a revisão da literatura sobre desvalorização por atraso, impulsividades e procrastinação e que permite o desenvolvimento das hipóteses. A terceira seção aborda os procedimentos metodológicos adotados; a quarta seção discute os

Perspectivas em Gestão \& Conhecimento, João Pessoa, v. 9, n. 1, p. 101-121, jan./abr. 2019. 
resultados alcançados pelo estudo e, por fim, a última seção traz as conclusões, limitações e sugestões para estudos futuros.

\section{REVISÃO DE LITERATURA E DESENVOLVIMENTO DE HIPÓTESES}

\subsection{Desvalorização por Atraso}

Desvalorização pelo atraso ou Delay Discounting, representa um comportamento no qual as pessoas aceitam receber valores de forma imediata na medida em que o prazo para este recebimento se torna distante. Também pode ser definido como a depreciação do valor de uma recompensa relacionada com o tempo com que o indivíduo leva para aceitar a recompensa.

Assim, considerando a definição de desvalorização pelo atraso, indivíduos que tendem a recusar o recebimento de recompensas mais adiante, apresentam um comportamento imediatista, mesmo que esperar para receber esta recompensa mais a frente seja mais vantajosa (MAR; ROBBINS, 2007). Thaler (1981), evidencia o efeito de diferentes atrasos considerando diferentes magnitudes sobre a taxa de desvalorização de estímulos apetitivos e aversivos através de um experimento com universitários. Nesse experimento, o autor comparou situações em que os participantes deveriam relatar que quantia de dinheiro recebida ou paga após um determinado período de tempo seria equivalente a uma quantia fixa a ser recebida ou paga imediatamente. $O$ resultado deste experimento apontou para uma desvalorização pelo atraso tanto na situação apetitiva quanto na situação aversiva. No entanto, a desvalorização na situação aversiva se mostrou muito menor do que na situação apetitiva, identificando o fenômeno que mais tarde ficou conhecido como assimetria ganhoperda (LOEWESTEIN; PRELEC, 1992; THALER, 1981).

Tal conclusão é importante para resultados dos outros dois experimentos descritos acima, uma vez que a taxa de desvalorização é muito menor na situação aversiva. $O$ uso de atrasos pequenos pode não resultar em uma desvalorização importante (THALER, 1981). Estudos recentes têm demonstrado diferenças quantitativas e qualitativas no modo como estímulos apetitivos e aversivos são influenciados pelo atraso. De uma maneira geral, os dados indicam que estímulos apetitivos são mais desvalorizados do que estímulos apetitivos (GONÇALVES, SILVA, 2015).

Além disso, para estímulos aversivos, nem sempre se encontra desvalorização, algumas pessoas consideram que uma situação aversiva imediata é preferida a uma atrasada, independentemente de sua magnitude. Embora experimentos da década de 60 já demonstrassem que algumas pessoas preferiam levar um choque imediato a um choque de mesma magnitude, porém atrasado, apenas recentemente as diferenças qualitativas entre estímulos apetitivos e aversivos vêm ganhando espaço na literatura (GONÇALVES; SILVA, 2015; MYERSON et al., 2016).

Outro dado interessante é que algumas pessoas apresentam um padrão inverso à desvalorização, ou seja, um estímulo aversivo se tornaria cada vez mais aversivo à medida que aumentasse o atraso (AINSLIE, 1975; APPELT et al., 2011; GONÇALVES; SILVA, 2015; MYERSON et al., 2016).

\subsection{Impulsividade}

Impulso é considerado uma necessidade forte, e por vezes irresistível, com a inclinação de agir sem deliberação ou planejamento (MCCOWN; DESIMONE, 1993), sendo gerado a partir da exposição a um certo estímulo. A impulsividade está relacionada a um padrão comportamental no qual, o indivíduo, manifesta suas respostas, cognitivas e motoras, sem

Perspectivas em Gestão \& Conhecimento, João Pessoa, v. 9, n. 1, p. 101-121, jan./abr. 2019. 
uma reflexão adequada, condicionando a um maior número de erros devido ao baixo foco de atenção e perceptivo na tarefa. Desta forma, os indivíduos impulsivos tendem a demonstrar falta de previsão das consequências de seus atos (MOLLER, 2011).

Desta forma no tocante do processo decisório, Caswell et al. (2015, p.68) compreendem a impulsividade como uma variedade de comportamentos que incluem decisões prematuras, propensas à gratificação imediata e que possuem resistência na inibição das respostas motoras.

Considerando a tomada de decisão, indivíduos autocontrolados apresentam maior probabilidade na escolha de alternativa atrasada, ou seja, quanto maior o tempo de escolha que o indivíduo é exposto, maior a chance de escolher esta opção. Por sua vez um indivíduo impulsivo na mesma situação, tenderia a escolher a alternativa imediata, mesmo de menor valor, em detrimento da alternativa atrasada de maior valor. Em uma situação aversiva, um indivíduo autocontrolado apresentaria maior probabilidade em escolher uma alternativa imediata de menor magnitude em detrimento de uma alternativa aversiva atrasada de maior magnitude. $\mathrm{O}$ indivíduo impulsivo tenderia a procrastinar, apresentando maior probabilidade na escolha da alternativa aversiva atrasada de maior magnitude, em detrimento da alternativa aversiva imediata de menor magnitude (AINSLIE, 1974).

O modelo Ainslie-Rachlin, aponta para dois fenômenos importantes para a compreensão do comportamento impulsivo. $O$ primeiro é que a preferência pelo reforçador imediato de menor magnitude não é constante ao longo do tempo, ou seja, dependendo do momento que fazemos a escolha, podemos fazer escolhas diferentes entre os mesmos reforçadores. O segundo é que escolhas antecipadas tendem a ser mais autocontroladas, enquanto escolhas próximas ao momento de apresentação do reforçador menor, no calor do momento, tendem a ser mais impulsivas. (MAZUR, 2014).

A desvalorização pelo atraso pode ser considerada uma definição operacional de impulsividade, que representa a perda do valor que uma recompensa sofre com o aumento do atraso para sua obtenção (YOON et al., 2007). A impulsividade é a preferência pelos resultados em curto prazo sobre recompensas futuras, mesmo quando ofertadas bonificações mais valiosas. No entanto, na procrastinação, a recompensa de longo prazo está associada a execução de uma ação pouco atrativa. Portanto, assim como acontece no comportamento impulsivo, o indivíduo escolhe uma atividade menos importante, porém mais prazerosa no curto prazo (VAN EERDE, 2000). Portanto, considerando que a desvalorização por atraso pode estar relacionada à impulsividade, elabora-se a seguinte hipótese: Hipótese $(\mathrm{H} 1)$ - a impulsividade influencia positivamente a desvalorização por atraso.

\subsection{Procrastinação}

A procrastinação é definida como um comportamento de se adiar tarefas, de se transferir atividades para "outro dia"; deixar de fazer algo ou, ainda, interromper o que deveria ser concluído dentro de um prazo determinado (KERBAUY, 1997). Significa atrasar ações vitais até que o desempenho e os resultados sejam maiores do que as atividades realizadas no tempo adequado.

A procrastinação pode ser temporária ou permanente. Também definida como uma função ao nível comportamental, adiamento do planejado, ao nível cognitivo, no qual há um adiamento da tomada de decisão (DEWITTE; LENS, 2000).

Desta forma, o indivíduo age por si mesmo se ter algum motivo de força maior que o impeça de realizar o que pretendia. Quando o indivíduo procrastina, ele não necessariamente compreende com clareza o que o leva a agir deste modo (KLINGSIECK, 2013). Este transtorno comportamental pode ser compreendido como um fenômeno que se manifesta no indivíduo de modo voluntário (RIBEIRO et al., 2014).

Perspectivas em Gestão \& Conhecimento, João Pessoa, v. 9, n. 1, p. 101-121, jan./abr. 2019. 
Fatores como falta de iniciativa, interesse, cansaço e preguiça e afetos negativos, como preocupação e expectativas muito altas acerca do próprio desempenho na tarefa procrastinada, conduzem o indivíduo ao adiamento da realização da atividade (GEARA, FILHO \& TEIXEIRA, 2017).

Portanto alguns elementos geradores da procrastinação foram identificados, por exemplo, como aversão a tarefa, atraso a execução da tarefa, baixa auto eficácia e impulsividade, assim como distração, autocontrole, falta de informação e organização (AKERLOF, 1991; BOICE, 1996; ELLIS; KNAUS, 1977; FERRARI, JOHNSON; MCCOWN, 1995; HAMASAKI; KERBAUY, 2001; KNAUS, 2000; MILGRAN, SROLOFF; ROSENBAUM, 1988; STRONGMAN; BURT, 2000). Estudos realizados por Chu e Choi (2005), apontam para os chamados procrastinadores ativos, que procrastinam suas decisões de forma consciente, utilizando o fato de deixarem a realização de tarefas para a última hora como fator motivador, podendo afetar a tomada de decisão. Portanto, formula-se a seguinte hipótese: Hipótese $(\mathrm{H} 2)$ - A procrastinação ativa afeta negativamente a desvalorização por atraso.

A procrastinação ativa também pode levar o indivíduo a perder oportunidades devido à tomada de decisão repentina. São quatro fatores que definem a procrastinação ativa, sendo: i) a preferência por pressão; ii) satisfação com os resultados; iii) habilidade em cumprir prazos e iv) decisão intencional (CHOI; MORAN, 2009).

Desta forma formulam-se as seguintes hipóteses: Hipótese (H2a) - A opção por pressão afeta negativamente a desvalorização por atraso; Hipótese $(\mathrm{H} 2 \mathrm{~b})$ - A satisfação com o resultado afeta negativamente a desvalorização por atraso; Hipótese $(\mathrm{H} 2 \mathrm{c})$ - A habilidade em cumprir prazos afeta negativamente a desvalorização por atraso; e Hipótese $(\mathrm{H} 2 \mathrm{~d})$ - A decisão intencional afeta negativamente a desvalorização por atraso.

\section{PROCEDIMENTOS METODOLÓGICOS}

A coleta de dados deste estudo foi realizada de forma transversal, pois os dados foram coletados em um só ponto no tempo e analisados (HAIR; ANDERSON; TATHAM; BLACK, 2009). O estudo utilizou técnicas quantitativas para análises dos resultados que buscam identificar relações dos comportamentos impulsivo e procrastinador na tomada de decisão financeira (MALHOTRA, 2001) com a utilização de instrumentos de medida desses fatores. A amostra do presente estudo é constituída por alunos do curso de administração abordando duas Instituições de ensino superior de caráter privado, localizadas na cidade de São Paulo.

Para este estudo foi utilizada uma amostra de 410 respondentes, sendo 350 respondentes pertencentes à Universidade $A$ e 60 respondentes pertencentes à Universidade $B$ de ambos os sexos, acima de 18 anos, em situação de adimplência e que sejam responsáveis por lidar com decisões financeiras no seu cotidiano. A amostra coletada supera os valores recomendados de amostra mínima preconizados por Hair et al. (2009) que estima que a amostra mínima contenha cinco a 10 para cada indicador do instrumento de medida. Os dados quantitativos foram analisados por meio do Statistical Package for the Social Sciences (SPSS) na versão 23.

\subsection{Instrumento de medidas}

Como o instrumento de coleta de dados, foi utilizado um questionário estruturado contendo perguntas fechadas, em ordem pré-estabelecida. Com a aplicação de uma survey com o objetivo de identificar se os fatores impulsividade e procrastinação afetam a desvalorização por atraso em um processo decisório.

A aplicação da survey foi realizada com estudantes de duas Instituições de ensino superior de caráter privado, localizada na cidade de São Paulo, onde foram aplicados cinco

Perspectivas em Gestão \& Conhecimento, João Pessoa, v. 9, n. 1, p. 101-121, jan./abr. 2019. 
cenários de ofertas monetárias para que o respondente faça a opção entre aceitar o pagamento de um determinado valor de forma imediata ou aceitar um valor maior em um prazo maior. Os resultados foram comparados com a decisão real de oferta de desconto aplicado sobre a matrícula dos estudantes das cinco unidades que compõem a instituição de ensino superior, considerando apenas os respondentes da universidade A denominada neste estudo.

Foi aplicado um questionário auto preenchível, de forma presencial aos participantes, sendo composto por uma parte introdutória explicando o objetivo da pesquisa, a garantia de sigilo e o uso dos resultados apenas como base dados para uma investigação científica, caso o participante autorize. Foi apresentado o nome da instituição, o nome do autor da pesquisa e os seus contatos.

\subsection{Escala de Impulsividade BIS 11 e Escala de Procrastinação EPA}

Para medir o grau de impulsividade do indivíduo parte da amostra, foi utilizada a Escala Barrat de Impulsividade BIS 11 (BARRAT, 1995), composta por três construtos definidos como dimensão motora, de atenção e falta de planejamento.

Quadro 1 - Tipos de Impulsividade Escala BIS11

\begin{tabular}{|l|l|}
\hline \multicolumn{1}{|c|}{ Dimensões } & \multicolumn{1}{c|}{ Definição do Construto } \\
\hline Motora & $\begin{array}{l}\text { Relacionada com a não inibição de respostas } \\
\text { incoerentes com o contexto, ou seja, agir sem } \\
\text { premeditação. }\end{array}$ \\
\hline Atenção & Relacionada à tomada de decisão rápida. \\
\hline Falta de Planejamento & $\begin{array}{l}\text { Engloba comportamentos orientados para o } \\
\text { presente. }\end{array}$ \\
\hline
\end{tabular}

Fonte: Barrat (1965)

A Escala BIS 11 foi adaptada e validada para o Brasil, por Diemen, Szobot, Kessler e Pechansky (2007) e traduzida e adaptada para o Brasil, por Malloy-Diniz et al., (2010), tendo os índices de consistência interna variando entre 0,79 e 0,82, que de acordo com Hair, Black, Babin, Anderson e Tatham (2009), valores superiores a 0,60, são considerados aceitáveis.

Dentre as escalas de auto relato desenvolvidas com o objetivo de avaliar a impulsividade, a Escala de Impulsividade de Barrat BIS-11 é um dos 39 instrumentos mais utilizados desde seu desenvolvimento a mais de 50 anos (MILLER et al., 2004; STANFORD et al., 2009).

A Escala de procrastinação EPA é utilizada para avaliar a procrastinação ativa. (CHU; $\mathrm{CHOI}, 2005)$. Esta escala está distribuída em 4 construtos, composta por 16 itens, utilizando uma estrutura tetra fatorial avaliando o comportamento procrastinador. As respostas dos itens são fornecidas em uma escala tipo likert de 7 pontos, variando entre 1 - Concordo Totalmente a 7 - Discordo Totalmente.

Por se tratar de uma escala originalmente construída no idioma inglês, será utilizada a versão adaptada para o português (GOUVEIA, 2014). Para este estudo foram utilizados os quatro construtos sendo Preferência por Pressão PPP; Satisfação com os Resultados SCR Habilidade em cumprir prazos HCP e Decisão Intencional (DI). 
Quadro 2 - Fatores que definem a procrastinação ativa

\begin{tabular}{|c|}
\hline Preferência por Pressão (PPP) \\
\hline $\begin{array}{l}\text { Este fator considera o estresse como elemento, que é motivado pela necessidade de lidar com } \\
\text { desafios e por demandas externas para completar a tarefa no tempo determinado. De acordo com } \\
\text { Freedman e Edwards (1988), essa pressão pode desenvolver sentimentos de desafio. Os seguintes } \\
\text { itens ilustram a questão: "É realmente difícil para mim trabalhar sabendo que os prazos estão } \\
\text { próximos" e "Fico chateado e relutante para agir quando sou forçado a trabalhar sob pressão". }\end{array}$ \\
\hline Satisfação com os Resultados (SCR) \\
\hline $\begin{array}{l}\text { Os indivíduos que procrastinam tendem a se motivar, quando, sob pressão conseguem executar as } \\
\text { tarefas em tempo hábil, obtendo resultados satisfatórios. Desta forma, procrastinadores ativos } \\
\text { decidem de forma intencional adiar suas tarefas, postergando para o último momento a execuça de } \\
\text { tarefas com o objetivo de utilizar de forma eficaz seu tempo para obter um resultado gratificante. } \\
\text { Dois dos itens que representam este fator são: "Meu desempenho tende a piorar quando tenho que } \\
\text { correr para cumpri prazos" e "Não me saio bem se tenho que fazer minhas atividades às pressas". }\end{array}$ \\
\hline Habilidade em cumprir prazos (HCP) \\
\hline $\begin{array}{l}\text { Procrastinadores ativos são capazes de determinar corretamente um tempo mínimo e necessário } \\
\text { para a conclusão de uma tarefa, por meio da utilização de estratégia de enfrentamento sob estresse } \\
\text { para atingir seu objetivo com sucesso. Os fatores que descrevem esta questão são: "Quando começo } \\
\text { alguma atividade, tenho dificuldade em termina-la" e com "Com frequência não consigo cumprir } \\
\text { metas que estabeleço para mim mesmo". }\end{array}$ \\
\hline Decisão intencional (DI) \\
\hline $\begin{array}{l}\text { Procrastinadores tendem a alternar de uma atividade para a outra sem se preocupar com o } \\
\text { planejamento ou organização do tempo. Estão dispostos a adiar tarefas que planejam executar, } \\
\text { alterando sua programação mesmo no curto prazo. Os fatores que permitem representar este fator } \\
\text { são: "Adio de propósito minhas atividades para usar meu tempo mais eficientemente" e "Adio }\end{array}$ \\
\hline
\end{tabular}

Fonte: Gouveia (2014)

\subsection{Questões de desvalorização por atraso}

As questões de desvalorização por atraso que fazem parte deste estudo, foram baseadas no experimento realizado por Rachlin, Rainieri e Cross (1991). Analisou-se o fenômeno da desvalorização por atraso por meio de cinco cenários decisórios com prazos estabelecidos de um a trinta e seis meses, conforme o Quadro 3: 
Quadro 3 - Ofertas dos experimentos de desvalorização por Atraso

\begin{tabular}{|c|c|c|c|c|c|c|c|c|c|}
\hline \multirow{2}{*}{\multicolumn{2}{|c|}{$\begin{array}{l}\text { Cenário I } \\
\text { Ofertas }\end{array}$}} & \multirow{2}{*}{\multicolumn{2}{|c|}{$\begin{array}{c}\text { Cenário II } \\
\text { Ofertas }\end{array}$}} & \multirow{2}{*}{\multicolumn{2}{|c|}{$\begin{array}{c}\text { Cenário III } \\
\text { Ofertas }\end{array}$}} & \multirow{2}{*}{\multicolumn{2}{|c|}{$\begin{array}{c}\text { Cenário IV } \\
\text { Ofertas }\end{array}$}} & \multirow{2}{*}{\multicolumn{2}{|c|}{$\begin{array}{c}\text { Cenário V } \\
\text { Ofertas }\end{array}$}} \\
\hline & & & & & & & & & \\
\hline Agora & $\begin{array}{c}1 \\
\text { mês }\end{array}$ & Agora & $\begin{array}{c}2 \\
\text { meses }\end{array}$ & Agora & $\begin{array}{c}6 \\
\text { meses }\end{array}$ & Agora & $\begin{array}{c}12 \\
\text { meses }\end{array}$ & Agora & $\begin{array}{c}36 \\
\text { meses }\end{array}$ \\
\hline \multicolumn{10}{|c|}{ Valores expressos em R\$̦ } \\
\hline 497,50 & 500,00 & 425,00 & 500,00 & 450,00 & 500,00 & 425,00 & 500,00 & 400,00 & 500,00 \\
\hline 495,00 & 500,00 & & & 425,00 & 500,00 & 400,00 & 500,00 & 375,00 & 500,00 \\
\hline 475,00 & 500,00 & & & 400,00 & 500,00 & 375,00 & 500,00 & 350,00 & 500,00 \\
\hline 450,00 & 500,00 & & & 375,00 & 500,00 & 350,00 & 500,00 & 325,00 & 500,00 \\
\hline 425,00 & 500,00 & & & 350,00 & 500,00 & 325,00 & 500,00 & 300,00 & 500,00 \\
\hline 400,00 & 500,00 & & & 325,00 & 500,00 & 300,00 & 500,00 & 275,00 & 500,00 \\
\hline 375,00 & 500,00 & & & 300,00 & 500,00 & 275,00 & 500,00 & 250,00 & 500,00 \\
\hline
\end{tabular}

Fonte: Rachlin, Rainieri e Cross (1991)

\subsection{Operacionalização dos Experimentos}

Foram apresentadas a cada respondente cinco ofertas de cada cenário e que foram extraídas por meio da combinação aleatória das ofertas apresentadas no Quadro 3. Cada oferta foi apresentada por meio de uma única questão aos respondentes, considerando um cenário aversivo, por exemplo: "Você parcelou a compra de um televisor para pagamento em 6 meses. $O$ vendedor ofereceu duas opções para pagamento da primeira parcela sendo: A) Pagar $\mathrm{R} \$ 425,00$ agora; B) Pagar $\mathrm{R} \$ 500,00$ daqui dois meses.

Após a aplicação do questionário, os resultados foram comparados com as decisões de ofertas de renovação de matrícula de uma instituição de ensino superior privada localizada na cidade de São Paulo. O processo de renovação de matrícula inicia-se com quatro meses de antecedência ao início do próximo semestre, no qual é apresentada ao aluno uma proposta de renovação antecipada da matrícula no valor de $15 \%$ de desconto sobre o valor da mensalidade. Esta promoção fica vigente até dois meses antes do término das aulas, e o aluno pode optar em aceitar a oferta de $15 \%$ forma imediata ou decidir por postergar a tomada de decisão.

Foi utilizada a base de dados da instituição de ensino superior com as informações dos alunos que aceitaram a oferta de forma imediata ou postergaram a decisão. Estes dados resultantes das decisões de ofertas reais foram cruzados com os dados obtidos por meio do questionário, com o objetivo de comparação de possíveis diferenças nas decisões sobre as ofertas hipotéticas e reais, cujos resultados estão apresentados nos tópicos posteriores. 


\section{DISCUSSÃO DOS RESULTADOS}

\subsection{Teste de comparação entre grupos de respondentes por instituição}

A mediana dos escores médios dos indicadores de cada construto, desvio-padrão e a significância do teste de Mann- Whitney para cada construto considerando os respondentes dos Grupos universidade A e universidade B, obtiveram p-valor inferior a 0,05. Somente dois construtos obtiveram diferenças significantes ( $p$-valor acima de 0,05 ) entre as medianas, portanto optou-se por considerar a universidade $A$ e universidade $B$ como um único grupo para efeito de análises posteriores dos construtos.

Somente dois construtos obtiveram diferenças significantes entre as medianas, portanto optou-se por considerar a universidade $A$ e universidade $B$ como um único grupo para efeito de análises posteriores dos construtos.

\subsection{Teste de comparação entre ofertas experimentais e oferta real}

Com o objetivo de compararmos os resultados obtidos entre os grupos que tomam a decisão financeira e aqueles que não tomam a decisão financeira foi aplicado o Teste Quiquadrado.

De acordo com os resultados obtidos ( $p$-valor $=0,39$ ), não há diferença estatisticamente significante entre o resultado da oferta hipotética com prazo de dois meses comparado com a oferta real da instituição de ensino.

Portanto podemos considerar que os resultados obtidos tanto no cenário da pesquisa quanto no cenário real, demonstram que as decisões nos cenários com valores financeiros semelhantes entre a oferta do caso real não podem ser consideradas como resultados estatisticamente distintos.

\subsection{Decisões das ofertas por período}

O Gráfico 1 apresenta os percentuais de respostas fornecidas considerando os valores dos descontos aplicados as ofertas monetárias em cada cenário, no qual o respondente foi submetido a duas situações, aceitando de forma imediata ou não o valor proposto.

Nota-se que no primeiro valor do experimento $\mathrm{R} \$ 2,50$ foram apresentados aos respondentes dois cenários no qual processo decisório ficou entre aceitar um valor de $\mathrm{R} \$ 497,50$ de forma imediata ou aceitar um valor de $\mathrm{R} \$ 500,00$ em um mês. O valor do desconto entre os primeiros valores ofertados é de $\mathrm{R} \$ 2,50$, o que podemos pressupor que em termos de desconto baixo, o percentual de indivíduos que aceitam o valor de forma imediata é similar ao percentual dos indivíduos que decidiram não aceitar o valor de forma imediata. Portanto, não é possível afirmar que o efeito da desvalorização por atraso acontece para valores mínimos de desconto aplicado.

Esta questão é importante, pois os resultados do questionário para um cenário de um mês convergem com os experimentos realizados por Thaler (1981), que afirma que a taxa de desvalorização é menor na situação aversiva, e a aplicação de valores pequenos pode não resultar em uma desvalorização importante. 
Gráfico 1 - Percentual de respondentes que aceitaram o desconto - 1 Mês de Prazo $100 \%$

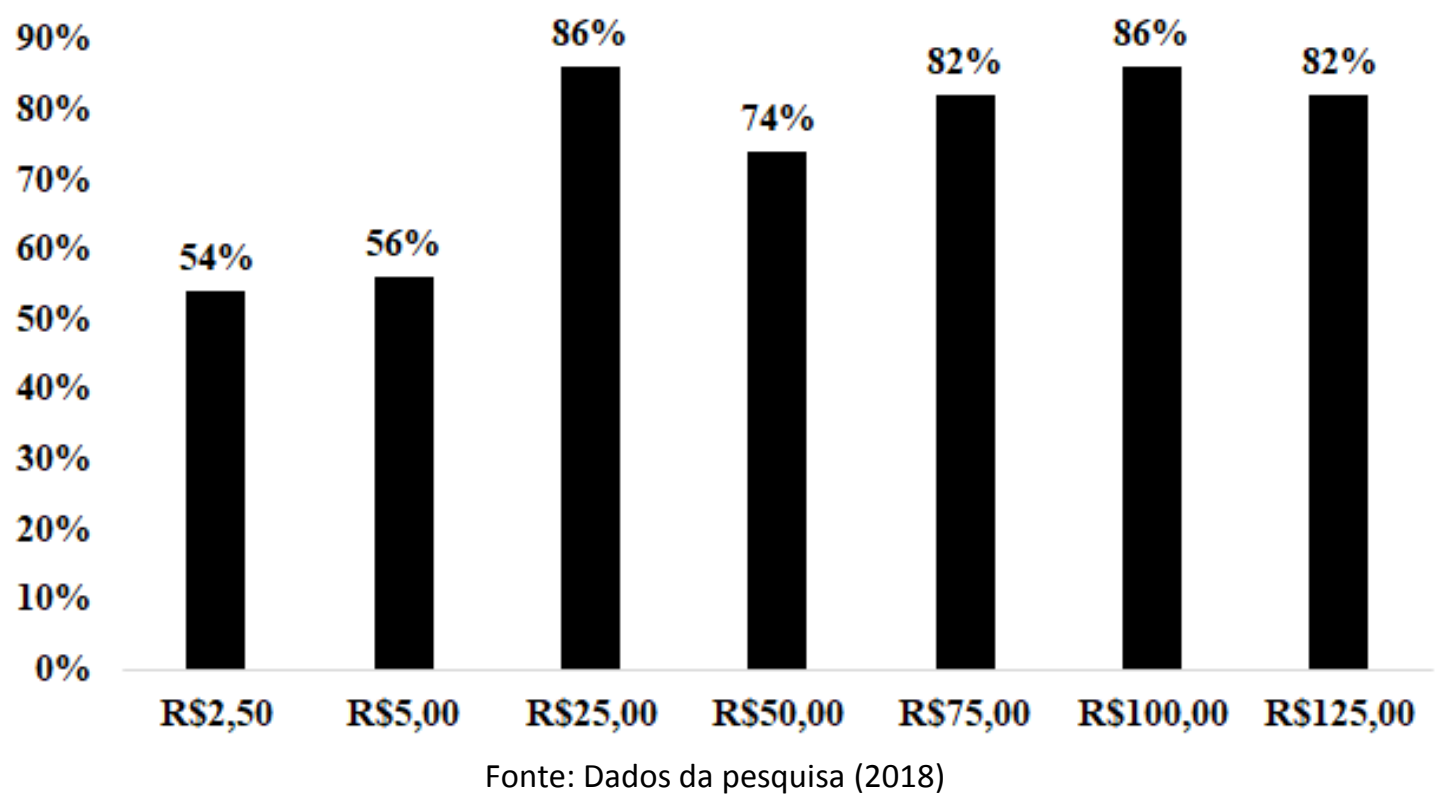

Considerando o valor de $\mathrm{R} \$ 25,00$ até o valor de $\mathrm{R} \$ 125,00$, a diferença no percentual de respondentes que aceitam o valor de forma imediata aumenta consideravelmente, apresentando um valor de desconto de $\mathrm{R} \$ 25,00$ entre cada valor monetário apresentado na oferta. Portanto, o resultado apresentado demonstra que os respondentes são sensíveis a valores maiores considerando a influência de um mês na tomada de decisão monetária, no qual o indivíduo deve ou não aceitar a oferta de forma imediata. Verifica-se também o aumento do percentual de aceitação ao desconto principalmente considerando a variação de $400 \%$ entre a diferença do segundo valor ofertado $(R \$ 5,00)$ e o terceiro valor ofertado $(\mathrm{R} \$ 25,00)$.

Ressalta-se que a variação entre o segundo valor monetário apresentado de $\mathrm{R} \$ 5,00$ e o terceiro valor monetário de $\mathrm{R} \$ 25,00$ foi de $20 \%$, conforme o Gráfico 1 . Os resultados corroboram com os estudos realizados por Rachlin, Rainieri e Cross (1991), que demonstram que o efeito da desvalorização por atraso chamado de ponto de inferência ocorre após a diferença percentual entre ofertas atingir o valor mínimo de $20 \%$. Tal percentual de ativação do ponto de inferência ficou evidenciado conforme o Gráfico 2.

O resultado apresentado no Gráfico 2 demonstra que o primeiro valor aplicado de $\mathrm{R} \$ 50,00$ sensibilizou parcialmente os respondentes no qual $50 \%$ optaram por aceitar o valor de forma imediata e os outros $50 \%$ aceitaram desvalorizar o valor oferecido. Após o aumento de $\mathrm{R} \$ 25,00$ (desconto aplicado) entre as ofertas os níveis de aceitação apresentam aumento no grau de aceitação do desconto. Demonstrando que, para o cenário de seis meses, podemos considerar que existe uma tendência de desvalorização do atraso, indicando sinais de comportamento impulsivo. 
Gráfico 2 - Percentual de respondentes que aceitaram o desconto - 6 Meses de Prazo

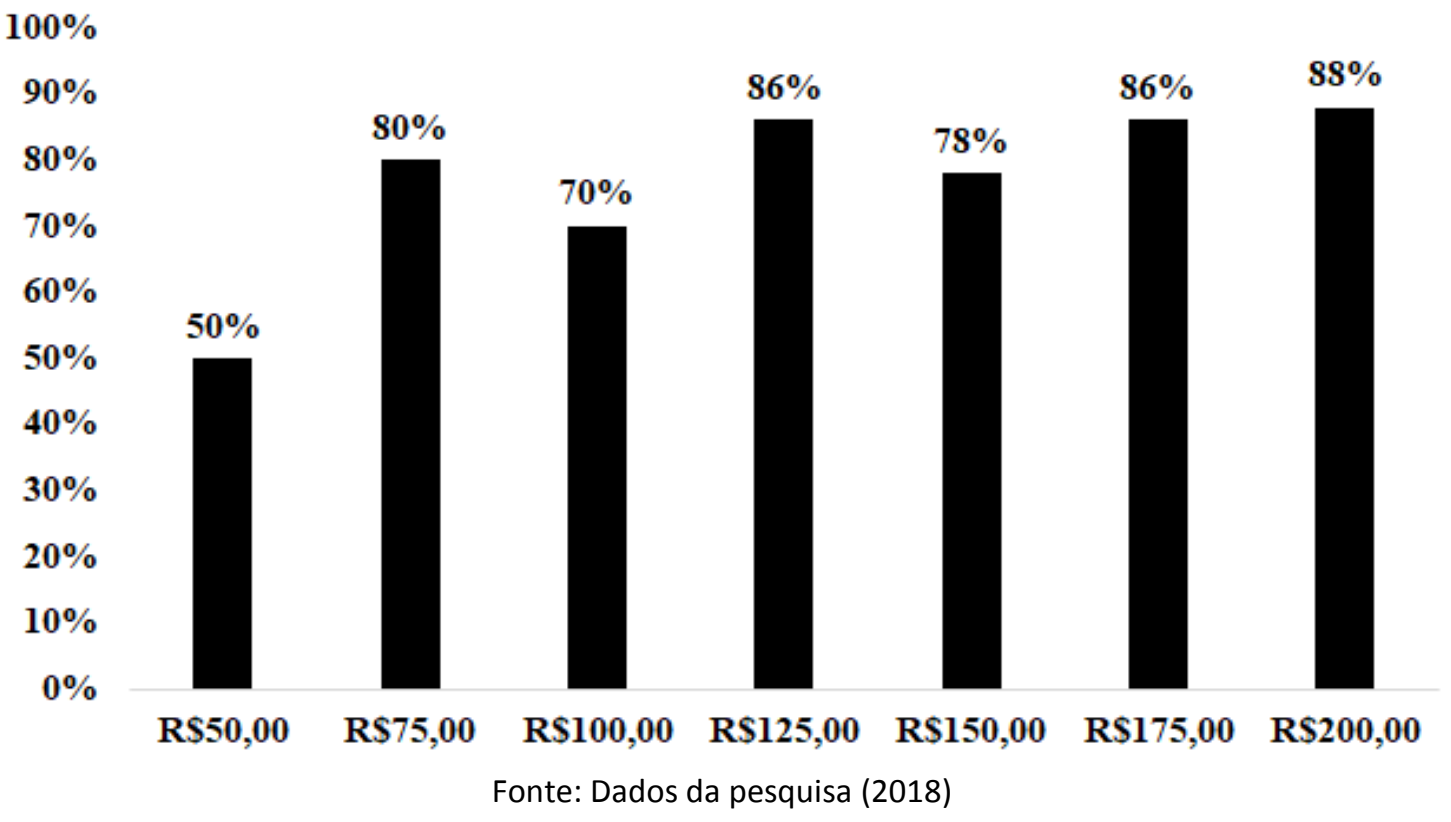

O percentual de variação entre os descontos considerando o valor de $\mathrm{R} \$ 75,00$ até o valor de $\mathrm{R} \$ 200,00$ o percentual de desconto é superior a $20 \%$. Portanto, nota-se que o percentual dos indivíduos que aceitam a desvalorização é potencializado, onde podemos pressupor que o fator tempo considerando um mês, dois meses e seis meses, podem comportamento impulsivo e pode afetar a tomada de decisão financeira.

Os resultados apresentados para o cenário de doze meses demonstram uma tendência de decréscimo no percentual de aceitação do desconto, ou seja, podemos pressupor que o fator tempo, após doze meses pode influenciar a decisão financeira do indivíduo, conduzindoo a um comportamento procrastinador.

No entanto, as pessoas apresentam tendência a considerar o valor de um resultado pela quantidade de tempo que levam para obter o referido resultado. Os resultados do experimento para doze meses corroboram com os estudos de Myerson, Green, Hanson, Holt e Estle (2003), que afirmam que o valor da recompensa ou punição que está disponível imediatamente tem impacto maior no desempenho sobre o valor atrasado. Para prazos superiores no caso deste estudo, considerando seis meses, o efeito da diminuição na desvalorização do atraso se faz presente. 
Gráfico 3 - Percentual de respondentes que aceitaram o desconto - 12 Meses de Prazo

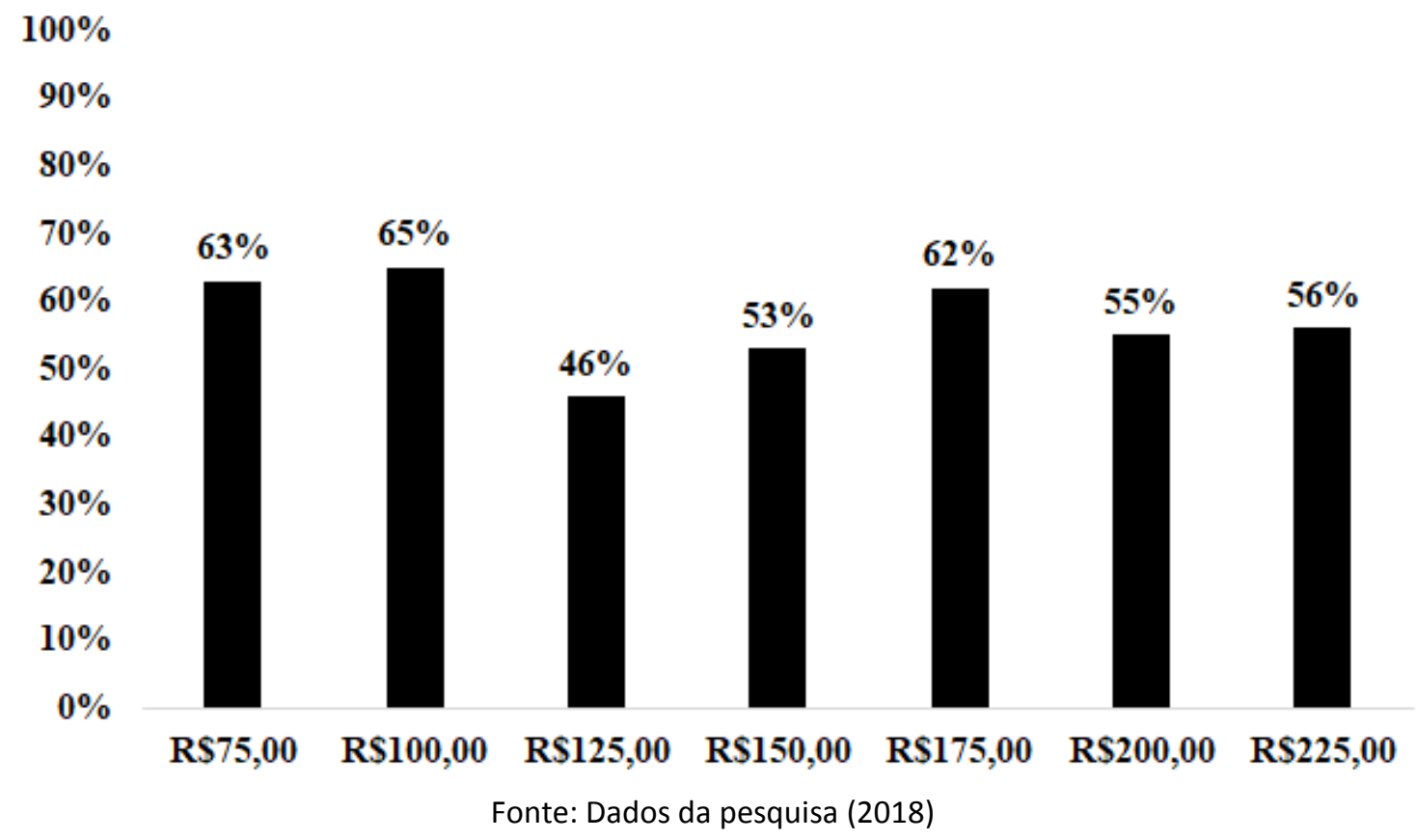

No gráfico 4, os resultados apresentados para o cenário de trinta e seis meses, assim como o cenário para doze meses, demonstram que quanto maior o tempo, há uma tendência quanto ao indivíduo em adiar sua tomada de decisão, evidenciando o comportamento procrastinador na tomada de decisão. Os resultados apresentados neste estudo corroboram com os estudos de Loewestein e Prelec (1992) e Thaler (1987) que afirmam que a desvalorização por atraso na situação aversiva é reduzida, identificando o fenômeno que mais ficou conhecido como assimetria-perda. 
Gráfico 4 - Percentual de respondentes que aceitaram o desconto - 36 Meses de Prazo.



Fonte: Dados da pesquisa, 2018

\subsection{Análise das hipóteses}

A técnica de Regressão Logística foi aplicada aos sete construtos, sendo três construtos que integram a escala de impulsividade e mais quatro construtos aplicados a escala de Procrastinação. Na Tabela 1, temos os resultados da regressão logística aplicada aos construtos de Impulsividade e Procrastinação para a oferta de um mês.

Tabela 1 - Resultado Regressão Logística - Prazo de oferta: um mês

\begin{tabular}{|c|c|c|c|c|c|c|c|c|c|c|}
\hline & $\begin{array}{l}\text { Impulsividade } \\
\text { Atencional }\end{array}$ & \begin{tabular}{|l} 
Falta de \\
Planejamento
\end{tabular} & \begin{tabular}{|l} 
Impulsividade \\
Motora
\end{tabular} & $\begin{array}{l}\text { Preferência } \\
\text { por Pressão }\end{array}$ & $\begin{array}{l}\text { Satisfação com } \\
\text { o Resultado }\end{array}$ & $\begin{array}{l}\text { Habilidade em } \\
\text { Cumprir Prazo }\end{array}$ & $\begin{array}{l}\text { Decisão } \\
\text { Intencional }\end{array}$ & & & \\
\hline Desconto & Beta (P-valor) & Beta (P-valor) & Beta (P-valor) & Beta (P-valor) & Beta (P-valor) & Beta (P-valor) & Beta (P-valor) & $\mathrm{R}^{2^{*}}$ & $H \& L^{*}$ & $n$ \\
\hline$R \$ \quad 2,50$ & $0,67(0,12)$ & $0,40(0,35)$ & $0,29(0,38)$ & $0,72(0,18)$ & $0,87(0,11)$ & $0,71(0,17)$ & $0,66(0,17)$ & 0,15 & 0,29 & 80 \\
\hline $\mathrm{R} \$ \quad 5,00$ & $0,44(0,36)$ & $0,32(0,48)$ & $0,11(0,78)$ & $0,31(0,43)$ & $0,15(0,71)$ & $0,56(0,83)$ & $0,57(0,98)$ & 0,20 & 0,93 & 50 \\
\hline$R \$ 25,00$ & $0,46(0,89)$ & $0,34(0,42)$ & $0,82(0,03)$ & $0,36(0,12)$ & $0,05(0,80)$ & $0,25(0,30)$ & $0,12(0,64)$ & 0,09 & 0,67 & 50 \\
\hline$R \$ 50,00$ & $0,36(0,48)$ & $0,97(0,25)$ & $0,78(0,16)$ & $0,26(0,60)$ & $0,21(0,74)$ & $0,56(0,28)$ & $0,26(0,04)$ & 0,11 & 0,32 & 80 \\
\hline $\mathrm{R} \$ \quad 75,00$ & $0,31(0,51)$ & $1,17(0,11)$ & $0,11(0,85)$ & $0,38(0,34)$ & $0,56(0,32)$ & $0,68(0,13)$ & $0,47(0,34)$ & 0,13 & 0,48 & 50 \\
\hline$R \$ 100,00$ & $0,06(0,90)$ & $0,34(0,74)$ & $0,67(0,25)$ & $0,68(0,15)$ & $1,00(0,07)$ & $0,05(0,90)$ & $0,14(0,76)$ & 0,13 & 0,07 & 50 \\
\hline$R \$ 125,00$ & $0,10(0,80)$ & $0,59(0,18)$ & $0,43(0,35)$ & $0,04(0,91)$ & $0,02(0,96)$ & $0,24(0,58)$ & $0,06(0,05)$ & 0,06 & 0,29 & 50 \\
\hline
\end{tabular}

Fonte: Dados da pesquisa (2018)

Perspectivas em Gestão \& Conhecimento, João Pessoa, v. 9, n. 1, p. 101-121, jan./abr. 2019. 
Os resultados apresentados na Tabela 1 demostram que apesar da impulsividade estar presente no comportamento dos respondentes, os índices de significância dos construtos de impulsividade demonstram valor superior a 0,05 e, portanto, neste estudo não se pode afirmar que a impulsividade possa afetar a tomada de decisão financeira, considerando uma significância estatística de 5\%.

Tabela 2 - Resultado Regressão Logística - Prazo de oferta: dois meses

\begin{tabular}{l|l|l|l|l|l|l|l|l|l|l}
\hline & $\begin{array}{c}\text { Impulsividade } \\
\text { Atencional }\end{array}$ & $\begin{array}{c}\text { Falta de } \\
\text { Planejamento }\end{array}$ & $\begin{array}{c}\text { Impulsividade } \\
\text { Motora }\end{array}$ & $\begin{array}{c}\text { Preferência } \\
\text { por Pressão }\end{array}$ & $\begin{array}{c}\text { Satisfação com } \\
\text { o Resultado }\end{array}$ & $\begin{array}{l}\text { Habilidade em } \\
\text { Cumprir Prazo }\end{array}$ & $\begin{array}{c}\text { Decisão } \\
\text { Intencional }\end{array}$ & \multicolumn{2}{|c|}{} \\
\hline Desconto & Beta (P-valor) & Beta (P-valor) & Beta (P-valor) & Beta (P-valor) & Beta (P-valor) & Beta (P-valor) & Beta (P-valor) & $R^{2}$ & $H_{\&} L^{*}$ & $n$ \\
\hline$R \$ 75,00$ & $0,24(0,86)$ & $0,11(0,51)$ & $0,05(0,75)$ & $0,01(0,92)$ & $0,21(0,10)$ & $0,01(0,96)$ & $0,14(0,22)$ & 0,27 & 0,58 & 50 \\
\hline
\end{tabular}

Fonte: Dados da pesquisa (2018)

$\mathrm{Na}$ segunda Tabela, os construtos de impulsividade e procrastinação não demonstraram valores estatisticamente significantes para o experimento com o prazo de dois meses, portanto os resultados apresentados não podem ser considerados conclusivos sobre a influência da impulsividade e da procrastinação considerando o valor da oferta para dois meses.

Na Tabela 3, no qual a oferta apresentada é para seis meses, os resultados dos construtos de impulsividade não apresentaram valores significantes, portanto não podendo concluir-se que impulsividade considerando a oferta para o prazo de seis meses possa afetar a tomada de decisão. Os construtos de procrastinação apresentaram resultados significantes para a oferta de seis meses, portanto indicando que o comportamento procrastinador pode afetar a tomada de decisão financeira em cenários aversivos de decisão.

Tabela 3 - Resultado Regressão Logística - Prazo de oferta: seis meses

\begin{tabular}{l|l|l|l|l|l|l|l|l|l|l}
\hline & $\begin{array}{c}\text { Impulsividade } \\
\text { Atencional }\end{array}$ & $\begin{array}{c}\text { Falta de } \\
\text { Planejamento }\end{array}$ & $\begin{array}{c}\text { Impulsividade } \\
\text { Motora }\end{array}$ & $\begin{array}{c}\text { Preferência } \\
\text { por Pressão }\end{array}$ & $\begin{array}{c}\text { Satisfação com } \\
\text { o Resultado }\end{array}$ & $\begin{array}{l}\text { Habilidade em } \\
\text { Cumprir Prazo }\end{array}$ & $\begin{array}{c}\text { Decisão } \\
\text { Intencional }\end{array}$ & \multicolumn{3}{|l}{} \\
\hline Desconto & Beta (P-valor) & Beta (P-valor) & Beta (P-valor) & Beta (P-valor) & Beta (P-valor) & Beta (P-valor) & Beta (P-valor) & $R^{2 *}$ & H\& $L^{*}$ & $n$ \\
\hline $\mathrm{R} \$ 50,00$ & $0,67(0,82)$ & $1,04(0,13)$ & $0,38(0,91)$ & $0,12(0,65)$ & $0,34(0,16)$ & $0,22(0,37)$ & $0,07(0,97)$ & 0,15 & 0,06 & 80 \\
\hline $\mathrm{R} \$ 75,00$ & $0,52(0,25)$ & $0,32(0,97)$ & $0,28(0,55)$ & $0,20(0,62)$ & $0,14(0,74)$ & $0,11(0,05)$ & $0,63(0,12)$ & 0,10 & 0,17 & 50 \\
\hline $\mathrm{R} \$ 100,00$ & $0,87(0,85)$ & $0,47(0,92)$ & $0,15(0,71)$ & $0,01(0,98)$ & $0,15(0,73)$ & $0,40(0,27)$ & $0,38(0,25)$ & 0,06 & 0,29 & 50 \\
\hline $\mathrm{R} \$ 125,00$ & $0,28(0,67)$ & $0,57(0,50)$ & $0,59(0,31)$ & $0,69(0,21)$ & $1,26(0,05)$ & $0,35(0,04)$ & $0,36(0,41)$ & 0,13 & 0,7 & 80 \\
\hline $\mathrm{R} \$ 150,00$ & $0,26(0,63)$ & $0,23(0,74)$ & $0,31(0,57)$ & $0,04(0,05)$ & $0,09(0,84)$ & $0,36(0,45)$ & $0,43(0,23)$ & 0,06 & 0,2 & 50 \\
\hline $\mathrm{R} \$ 175,00$ & $0,47(0,31)$ & $0,21(0,81)$ & $0,19(0,72)$ & $0,52(0,29)$ & $0,85(0,05)$ & $0,23(0,62)$ & $0,22(0,66)$ & 0,09 & 0,25 & 50 \\
\hline $\mathrm{R} \$ 200,00$ & $0,14(0,78)$ & $0,52(0,59)$ & $0,29(0,57)$ & $0,02(0,05)$ & $0,09(0,84)$ & $0,24(0,57)$ & $0,97(0,82)$ & 0,02 & 0,45 & 50 \\
\hline
\end{tabular}

Fonte: Dados da pesquisa (2018) 
Na Tabela 3, seis resultados apresentam significância estatística para os construtos de procrastinação entre os valores aplicados que variam entre $\mathrm{R} \$ 75,00$ a $\mathrm{R} \$ 200,00$.

Desta forma, pressupõem-se que o comportamento procrastinador pode estar presente e afeta a tomada de decisão financeira. Esta condição indica que em um cenário aversivo onde ocorre a perda, o tomador de decisão que apresenta comportamento procrastinador, pode considerar o tempo como fator de influência em sua decisão.

Tabela 4 - Resultado Regressão Logística - Prazo de oferta: doze meses

\begin{tabular}{|c|c|c|c|c|c|c|c|c|c|c|}
\hline & $\begin{array}{l}\text { Impulsividade } \\
\text { Atencional }\end{array}$ & $\begin{array}{c}\text { Falta de } \\
\text { Planejamento }\end{array}$ & $\begin{array}{c}\text { Impulsividade } \\
\text { Motora }\end{array}$ & $\begin{array}{l}\text { Preferência } \\
\text { por Pressão }\end{array}$ & $\begin{array}{c}\text { Satisfação com } \\
\text { o Resultado }\end{array}$ & $\begin{array}{l}\text { Habilidade em } \\
\text { Cumprir Prazo }\end{array}$ & $\begin{array}{c}\text { Decisão } \\
\text { Intencional }\end{array}$ & & & \\
\hline Desconto & Beta (P-valor) & Beta (P-valor) & Beta (P-valor) & Beta (P-valor) & Beta (P-valor) & Beta (P-valor) & Beta (P-valor) & $\mathrm{R}^{2 *}$ & $H \& L^{*}$ & $n$ \\
\hline$R \$ 75,00$ & $0,86(0,40)$ & $0,30(0,95)$ & $0,89(0,20)$ & $1,42(0,25)$ & $1,42(0,25)$ & $1,19(0,47)$ & $1,30(0,21)$ & 0,20 & 0,19 & 50 \\
\hline$R \$ 100,00$ & $0,87(0,77)$ & $0,79(0,04)$ & $0,65(0,85)$ & $0,68(0,79)$ & $0,30(0,20)$ & $0,30(0,25)$ & $0,25(0,06)$ & 0,11 & 0,96 & 80 \\
\hline$R \$ 125,00$ & $0,55(0,32)$ & $0,69(0,31)$ & $0,95(0,05)$ & $2,27(0,00)$ & $2,27(0,00)$ & $2,29(0,01)$ & $2,03(0,00)$ & 0,20 & 0,57 & 50 \\
\hline$R \$ 150,00$ & $0,72(0,26)$ & $0,52(0,42)$ & $0,74(0,20)$ & $0,17(0,77)$ & $0,08(0,05)$ & $0,39(0,40)$ & $0,92(0,05)$ & 0,20 & 0,57 & 50 \\
\hline$R \$ 175,00$ & $0,96(0,16)$ & $2,10(0,12)$ & $0,95(0,11)$ & $0,09(0,81)$ & $0,57(0,02)$ & $0,82(0,02)$ & $0,34(0,05)$ & 0,12 & 0,19 & 80 \\
\hline$R \$ 200,00$ & $0,84(0,32)$ & $0,05(0,95)$ & $1,37(0,12)$ & $0,53(0,33)$ & $0,04(0,03)$ & $0,48(0,51)$ & $0,65(0,16)$ & 0,14 & 0,53 & 50 \\
\hline $\mathrm{R} \$ 225,00$ & $0,16(0,73)$ & $0,39(0,69)$ & $0,06(0,91)$ & $0,56(0,37)$ & $0,94(0,18)$ & $0,08(0,01)$ & $0,87(0,05)$ & 0,09 & 0,61 & 50 \\
\hline
\end{tabular}

Fonte: Dados da pesquisa (2018)

Observa-se na Tabela 5 que os construtos de impulsividade não apresentam resultados significantes e observa-se que o comportamento impulsivo neste estudo pode não afetar a tomada de decisão financeira em cenários aversivos de decisão. 
Tabela 5 - Resultado Regressão Logística - Prazo de oferta: trinta e seis meses

\begin{tabular}{|c|c|c|c|c|c|c|c|c|c|c|}
\hline & $\begin{array}{l}\text { Impulsividade } \\
\text { Atencional }\end{array}$ & $\begin{array}{c}\text { Falta de } \\
\text { Planejamento }\end{array}$ & $\begin{array}{c}\text { Impulsividade } \\
\text { Motora }\end{array}$ & $\begin{array}{l}\text { Preferência } \\
\text { por Pressão }\end{array}$ & $\begin{array}{c}\text { Satisfação com } \\
\text { o Resultado }\end{array}$ & $\begin{array}{l}\text { Habilidade em } \\
\text { Cumprir Prazo }\end{array}$ & $\begin{array}{c}\text { Decisão } \\
\text { Intencional }\end{array}$ & & & \\
\hline Desconto & Beta (P-valor) & Beta (P-valor) & Beta (P-valor) & Beta (P-valor) & Beta (P-valor) & Beta (P-valor) & Beta (P-valor) & $\mathrm{R}^{2 *}$ & $H \& L^{*}$ & $n$ \\
\hline$R \$ 100,00$ & $0,21(0,65)$ & $0,71(0,36)$ & $0,20(0,69)$ & $0,67(0,18)$ & $0,58(0,01)$ & $0,53(0,20)$ & $0,26(0,61)$ & 0,13 & 0,94 & 50 \\
\hline$R \$ 125,00$ & $0,30(0,96)$ & $1,09(0,35)$ & $0,27(0,67)$ & $0,27(0,53)$ & $0,12(0,98)$ & $0,26(0,05)$ & $0,45(0,02)$ & 0,06 & 0,41 & 50 \\
\hline$R \$ 150,00$ & $0,27(0,58)$ & $0,68(0,16)$ & $0,97(0,05)$ & $0,44(0,23)$ & $0,10(0,05)$ & $0,23(0,53)$ & $0,20(0,57)$ & 0,11 & 0,15 & 80 \\
\hline$R \$ 175,00$ & $0,85(0,58)$ & $0,28(0,13)$ & $1,19(0,05)$ & $2,27(0,04)$ & $2,27(0,04)$ & $2,29(0,05)$ & $2,03(0,00)$ & 0,2 & 0,57 & 50 \\
\hline$R \$ 200,00$ & $0,29(0,63)$ & $0,38(0,60)$ & $0,94(0,05)$ & $0,71(0,14)$ & $0,46(0,00)$ & $0,73(0,05)$ & $0,07(0,05)$ & 0,21 & 0,31 & 50 \\
\hline $\mathrm{R} \$ 225,00$ & $1,12(0,18)$ & $0,08(0,92)$ & $0,48(0,51)$ & $0,02(0,96)$ & $0,81(0,19)$ & $0,63(0,24)$ & $0,90(0,12)$ & 0,15 & 0,84 & 80 \\
\hline$R \$ 250,00$ & $29,46(0,99)$ & $36,00(0,99)$ & $95,12(0,98)$ & $109,21(0,98)$ & $46,16(0,98)$ & $0,98(0,04)$ & $0,19(0,02)$ & 0,29 & 1,00 & 50 \\
\hline
\end{tabular}

Fonte: Dados da pesquisa, 2018

Porém, de acordo com a maioria dos resultados apresentados, nota-se que os construtos vinculados à procrastinação indicam que o comportamento procrastinador pode estar presente nos respondentes desta forma afetando a tomada de decisão financeira, principalmente considerando o construto de Decisão Intencional, no qual o indivíduo decide procrastinar de maneira deliberada.

Do ponto de vista acadêmico, o estudo das finanças comportamentais sobre a desvalorização por atraso, e a possível influência dos comportamentos de impulsividade e procrastinação, apresenta relevância, considerando que os estudos antes realizados tratam os temas de forma isolada como, por exemplo, estudos sobre a impulsividade e acidentes de trânsito (ARAUJO et al., 2008) e o tratamento farmacológico da impulsividade e do comportamento agressivo (PRADO-LIMA, 2009).

Considerando os estudos sobre procrastinação, podemos ressaltar os estudos sobre a procrastinação como um comportamento causador de problemas a saúde (HAMASAKI; KERBAUY, 2001), a procrastinação aplicada ao comportamento de estudantes e transeuntes de uma capital brasileira (ENUMO; KERBAUY, 1999) e o estudo sobre gênero e outras variáveis que influenciam a procrastinação acadêmica.

Portanto este estudo contribui com a associação de dois construtos comportamentais. Além de que, os estudos realizados associados a impulsividade e procrastinação são específicos da área clínica (BARBOSA, 2010; BERNARDES, BANACO; NETO, 2013; MATTA, GONÇALVES; BIZARRO, 2014). O Quadro 4 apresenta uma síntese dos testes de hipótese do estudo. 
Quadro 4 - Resultados das hipóteses

\begin{tabular}{|l|l|l|}
\hline \multicolumn{1}{|c|}{ Hipótese } & \multicolumn{1}{|c|}{ Descrição } & \multicolumn{1}{|c|}{ Resultado } \\
\hline $\mathrm{H} 1$ & $\begin{array}{l}\text { A impulsividade influencia positivamente a } \\
\text { desvalorização por atraso. }\end{array}$ & Não Confirmada \\
\hline $\mathrm{H} 2$ & $\begin{array}{l}\text { A procrastinação ativa afeta negativamente a } \\
\text { desvalorização por atraso. }\end{array}$ & $\begin{array}{l}\text { Confirmada } \\
\text { Parcialmente }\end{array}$ \\
\hline $\mathrm{H} 2 \mathrm{a}$ & $\begin{array}{l}\text { A opção por pressão afeta negativamente a } \\
\text { desvalorização por atraso. }\end{array}$ & $\begin{array}{l}\text { Confirmada } \\
\text { Parcialmente }\end{array}$ \\
\hline $\mathrm{H} 2 \mathrm{~b}$ & $\begin{array}{l}\text { A satisfação com o resultado afeta negativamente a } \\
\text { desvalorização por atraso. }\end{array}$ & $\begin{array}{l}\text { Confirmada } \\
\text { Parcialmente }\end{array}$ \\
\hline $\mathrm{H} 2 \mathrm{c}$ & $\begin{array}{l}\text { A habilidade em cumprir prazos afeta negativamente a } \\
\text { desvalorização por atraso. }\end{array}$ & $\begin{array}{l}\text { Confirmada } \\
\text { Parcialmente }\end{array}$ \\
\hline $\mathrm{H} 2 \mathrm{~d}$ & $\begin{array}{l}\text { A decisão intencional afeta negativamente a } \\
\text { desvalorização por atraso. }\end{array}$ & $\begin{array}{l}\text { Confirmada } \\
\text { Parcialmente }\end{array}$ \\
\hline
\end{tabular}

Fonte: Dados da pesquisa (2018)

\section{CONCLUSÕES}

Este estudo aprofunda a compreensão de características individuais na decisão individual financeira sob a ótica da desvalorização por atraso com o objetivo de mensurar a interferência do comportamento impulsivo por meio da concepção do modelo de pesquisa baseado na escala de impulsividade e procrastinação.

Os resultados apresentados demonstram que a maior parte dos respondentes, estão empregados e são responsáveis pela tomada de decisão financeira. Tais resultados são representativos para este estudo, pois estas condições podem influenciar diretamente a tomada de decisão financeira. Considera-se também o fato que os números obtidos se assemelham com o perfil médio da população brasileira, no que diz respeito a renda e nível de emprego e estão próximos aos percentuais da população brasileira.

A desvalorização por atraso aplicado ao estudo foi realizada por meio de experimento, em que foram coletados 410 questionários, aplicados a duas Instituições de ensino superior localizadas na cidade de São Paulo. Os resultados da pesquisa foram comparados com os resultados de uma oferta monetária real aplicada a amostra. Os resultados evidenciam que não há diferença entre os resultados do questionário e os resultados da oferta real, possibilitando a validação de que cenários hipotéticos podem ser utilizados em pesquisas que tratam de temas associados com decisões financeiras.

Esta condição de tomada de decisão em um cenário aversivo ficou evidenciada pelos resultados apresentados nesta pesquisa, no qual o tempo igual ou superior a doze meses, associado ao valor do desconto aplicado sendo igual ou superior a $15 \%$ do valor da oferta total conduzem o indivíduo ao comportamento de procrastinação. No entanto, os resultados desta pesquisa demonstram que a impulsividade apesar de possivelmente estar presente nos indivíduos, não foi possível evidenciá-lo como um comportamento que possa afetar a tomada de decisão em cenários aversivos.

Para os gestores, o estudo amplia o espectro de entendimento sobre dois componentes comportamentais: impulsividade e procrastinação, como fatores que podem anteceder a tomada de decisão financeira. Neste estudo ressalta-se que o comportamento impulsivo não foi detectado após análise dos resultados. Os resultados deste estudo podem contribuir para o planejamento de ações comerciais, na medida em que se busca compreender

Perspectivas em Gestão \& Conhecimento, João Pessoa, v. 9, n. 1, p. 101-121, jan./abr. 2019. 
em que momento a desvalorização ocorre, considerando o valor do desconto aplicado e o tempo.

Desta forma este estudo pode auxiliar os gestores a planejarem melhor suas ofertas junto ao público alvo, principalmente considerando um cenário aversivo.

Entende-se como limitação desta pesquisa, o local de obtenção da amostra do estudo, pois a coleta de dados restringiu-se a dois grupos pertencentes a duas instituições de ensino superior localizadas na cidade de São Paulo.

Portanto para estudos futuros sugere-se aplicar a pesquisa com outros grupos de outros segmentos, possibilitando uma ampliação da amostra da pesquisa, com o objetivo de apresentar novas perspectivas sobre o tema. Pode-se considerar a quantidade de respondentes da pesquisa como possível fator limitante, pois foram aplicados sete tipos de questionários divididos em cinco grupos com cinquenta respondentes e dois questionários com oitenta respondentes, desta forma amostras maiores podem evidenciar alguns efeitos cuja significância não foi detectada neste estudo.

A ausência de significância estatística por meio dos resultados obtidos pela aplicação da regressão logística para o comportamento impulsivo, exige cautela em sua análise, pois apesar do fenômeno de impulsividade estar presente, não foram conclusivos os resultados desta pesquisa que associavam tal comportamento à tomada de decisão financeira, mesmo tal comportamento sendo ilustrado por meio da representação gráfica da aplicação do questionário.

Também é importante considerarmos que outras questões como o custo de oportunidade e o valor do dinheiro ao longo do tempo são fatores que podem impactar na tomada de decisão financeira e influenciar diretamente o processo de desvalorização por atraso em um cenário aversivo. Nesse sentido, pesquisas futuras que abordem essas variáveis são podem aprofundar a compreensão nesse tema.

E por fim, sugere-se que outras variáveis de ordem macroeconômica e como cenário econômico, condição econômica entre países, processo inflacionário, renda, e fatores comportamentais como ansiedade, por exemplo, sejam incorporadas na análise de estudos futuros, buscando uma ampliação no espectro de variáveis que possam afetar a tomada de decisão financeira.

\section{REFERÊNCIAS}

AINSLIE, G. Impulse control in pigeons. Journal of the Experimental Analysis of Behavior, v. 21, p. 485-489, 1974.

AINSLIE, G. Specious reward: a behavioral theory of impulsiveness and impulse control. Psychological Bulletin, v. 82, n. 4, p. 463-496. 1975.

AKERLOF, G. A. Procrastination and obedience. The American Economic Review, v. 81, n.2, p. 11-19, 1991.

APPELT, K. C., HARDISTY D. J., \& WEBER, E. U. Asymmetric discounting of gains and losses: A query theory account. Journal of Risk and Uncertainty, v. 43, n. 2, p. 107-126. 2011.

ARAUJO, M. M.; MALLOY-DINIZ, L. F.; ROCHA, F. L. Impulsividade e acidentes de trânsito. Revista psiquiatria clínica, v. 36, n. 2, p. 60-68, 2009. 
BARRAT, E. S. Anxiety and impulsiveness related to psychomotor efficiency. Percept Mot Skills, v. 9, n. 2, p. 191-198, 1959.

BARRAT, E. S. Factor analysis of some psychometric measures of impulsiveness and anxiety. Psychological Reports, v. 16, p. 547-554, 1965.

BERNARDES, L. A.; BANACO, R. A.; NETO, D. M. R. Influência da disponibilidade de reforçadores com diferentes valores sobre respostas de autocontrole. Perspectivas, v. 4, n. 1, p. 001-008, 2013.

BOICE, R. Procrastination and blocking: A novel, practical approach. Westport: Praeger Publishers, 1996.

CAPPELLOZZA, A.; SANCHEZ, O. P. Análise de decisões sobre uso de tecnologia: um estudo no setor de telefonia móvel fundamentado nos axiomas da economia comportamental. Revista de Administração Contemporânea, v. 15, p. 1078-1099, 2011.

CASWELL, AMY.; ROD, THEODORA; MORGAN, MICHAEL. Further evidence of the heterogeneous nature of impulsivity. Personality and Individual Differences, v. 76, p. 68-74, 2015.

CHOI, J. N.; MORAN, S. V. Why not procrastinate? Development and validation of a new active procrastination scale. Journal of Social Psychology, v. 149, p. 195-211, 2009.

$\mathrm{CHU}$, A. H. C.; CHOI, J. N. Rethinking procrastination: Positive effects of "active" procrastination behavior on attitudes and performance. The Journal of Social Psychology, v. 145, p. 245-264, 2005.

DEWITTE, S.; LENS, W. Procrastinators lack a broad action perspective. European Journal of Personality, v. 14, n. 2, p. 121-140, 2000.

DIEMEN, L.; SZOBOT, C.M.; KESSLER, F.; PECHANSKY, F. Adaptation and construct validation of the Barratt impulsiveness scale (BIS-11) to Brazilian Portuguese for use in adolescents. Revista Brasileira de Psiquiatria, v. 29, n. 2, p. 153-166, 2007.

DITTMAR, H.; BEATTIE, J.; FRIESE, S. Objects, decision considerations and self-image in men's and women's impulse purchases. Acta Psychologica, v. 93, p. 187-206, 1996.

ELLIS, A.; KNAUS, W. Overcoming procrastination. New York: Institute for Rational Living, 1977.

ENUMO, S. R. F.; KERBAUY, R. R. Procrastinação: Descrição de comportamentos de estudantes e transeuntes de uma capital brasileira. Revista Brasileira de Terapia Comportamental e Cognitiva, v. 1, p. 125-133, 1999.

FERRARI, J.; EMMONS, R. Procrastination as revenge: Do people report using delays as a strategy for vengeance? Personality and Individual Differences, v. 18, n. 4, p. 539-544, 1994.

FERRARI, J. R.; JOHNSON, J. L.; MCCOWN, W. G. Procrastination and task avoidance: Theory, research and treatment. New York: Plenum, 1995.

Perspectivas em Gestão \& Conhecimento, João Pessoa, v. 9, n. 1, p. 101-121, jan./abr. 2019. 
GEARA, G. B.; TEIXEIRA FILHO, N. H.; Construção da escala de motivos da procrastinação acadêmica. Psico, v. 48, n. 2, p. 140-151. 2017.

GONÇALVES, F. L.; SILVA, M. T. A. Comparing individual delay discounting of gains and losses. Psychology \& Neuroscience, v. 8, n. 2, 267-279, 2015.

GOUVEIA, V. Escala de procrastinação ativa: Evidências de validade fatorial e consistência interna. Psico-USF, v. 19, n. 2, p. 345-354, 2014.

HAIR, J. R.; BLACK, W. C.; BABIN, B. J.; ANDERSON, R. E.; TATHAM, R. L. Análise multivariada de dados. São Paulo: Bookman, 2009.

HAMASAKI, E. I. M.; KERBAUY, R. R. Será o comportamento de procrastinar um problema de saúde? Revista Brasileira de Terapia Comportamental e Cognitiva, v. 3, n. 2, p. 35-40, 2001.

HARRIOTT, J. S.; FERRARI, J. R. Prevalence of Procrastination among Samples of adults. Psychological Reports, v. 78, p. 611-616, 1996.

KACHGAL, M. M.; HANSEN, L. S.; NUTTER, K. J. Academic procrastination prevention/intervention: Strategies and recommendations. Journal of Developmental Education, v. 15, p. 14-24, 2001.

KAHNEMAN, D.; TVERSKY, A. Prospect theory: An analysis of decision under risk. Econometrica, v. 47, p. 313-327, 1979.

KERBAUY, R. R. Procrastinação: adiamento de tarefas. In: BANACO, R. A. (Ed.). Sobre Comportamento e Cognição. Arbytes, 1997.

KLINGSIEK, K. B. Procrastination: When good things don't come to those who wait. European Psychologist, v. 18, n. 1, p. 24-34, 2013.

KNAUS, W. Procrastination, blame, and change. Journal of Social Behavior \& Personality, v. 15, n. 5, p. 153-166, 2000.

LOEWENSTEIN, G.; PRELEC, D. Anomalies in intertemporal choice: Evidence and interpretation. New York: Russel Sage Foundation, 1992.

MALHOTRA, N. K. Pesquisa de marketing: uma orientação aplicada. Porto Alegre: Bookman, 2001.

MAR, A. C.; ROBBINS, T. W. Delay discounting and impulsive choice in the rat. Current Protocols in Neuroscience. v. 39, n. (8), 2007.

MATTA, A., GONÇALVES, L. F.; BIZARRO, L. Desvalorização pelo atraso, dependência química e impulsividade. Avanços en Psicología Latinoamericana, v. 32, n. 2, p. 217-230, 2014.

MAZUR, J. Learning and Behavior. MCCOWN, W.; DESIMONE, P. Impulses, impulsivity, and impulsive behaviors: a historical review of a contemporary issue. In: McCOWN, W.; DeSIMONE, P. (Coord.). The impulsive client: Theory, research and treatment. Washington: American Psychological Association, 2003. 
MILGRAM, N.A.; SROLOFF, B.; ROSENBAUM, M. The procrastination of everyday life. Journal of Research in Personality, v. 14, n. 2, p. 141-156, 1988.

MOLLER, D. Wealth, disability and happiness. Philosophy \& Public Affairs, v. 39, n. 2, p. 177206, 2011.

MYERSON, J.; GREEN, L.; HANSON, J.; HOLT, D.; ESTLE, S. Discounting delayed and probabilistic rewards: Processes and traits. Journal of Economic Psychology, v. 24, n. 5, p. 619-635, 2003.

MYERSON, J.; BAUMANN, A. A.; GREEN, L. Individual Differences in Delay Discounting: Differences are Quantitative with Gains, but Qualitative with Losses. Journal of Behavioral Decision Making, 14, 1-14. 2016.

PRADO-LIMA, P. A. S Tratamento farmacológico da impulsividade e do comportamento agressivo. Revista Brasileira de Psiquiatria, v. 31, n. 2, p. 58-65, 2009.

RACHLIN, H.; RANIERI, A.; CROSS, D. Subjective probability and delay. Journal of the Experimental Analysis of Behavior, v. 55, p. 233-244, 1991.

RIBEIRO, F.; AVELINO, B. C.; COLAUTO, R. D.; CASA NOVA, S. P. C. Comportamento procrastinador e desempenho acadêmico de estudantes do curso de ciências contábeis. Advances in Scientific and Applied Accounting, v. 7, n. 3, p. 386-406, 2014.

STRONGMAN, K. T.; BURT, C. D. B. Taking breaks from work: An exploratory inquiry. Journal of Psychology, v. 134, p. 229-242, 2000.

THALER, R. H. Some empirical evidence on dynamic inconsistency. Economics Letter, p. 201207, 1981.

THALER, R. H. Further evidence on investor overreaction and stock market seasonality. The Journal of Finance, v. 42, p. 557-581, 1987.

VAN EERDE, W. Procrastination: Self-regulation in initiating aversive goals. Applied Psychology, v. 49, n. 3, p. 372-389, 2010.

WEYMANN, E. Procrastination in the workplace: Dispositional and situational determinants of delay behavior at work. Academy of Management Proceedings, p. 226-230, 1988.

Artigo recebido em 9/03/2018 e aceito para publicação em 12/01/2019 